\title{
LA COMICIDAD DE UN ENREDO: CON QUIEN VENGO, VENGO, DE CALDERÓN DE LA BARCA
}

\author{
Rebeca Lázaro Niso \\ Universidad de La Rioja \\ C/ San José de Calasanz, 33 \\ 26004, Logroño \\ España \\ rebeca.lazaro@unirioja.es
}

Con quien vengo, vengo es una de las muchas comedias de enredo de Calderón de la Barca a las que hasta el momento apenas se ha prestado suficiente atención. La poca bibliografía existente al respecto se reduce prácticamente a cuestiones relacionadas con su composición y proceso de transmisión textual ${ }^{1}$, o bien a alguna circunstancia de su puesta en escena ${ }^{2}$. No puede precisarse la fecha de su escritura, aunque ya

\footnotetext{
${ }^{1}$ Ver el reciente trabajo de Cruickshank, 2014, pp. 87-102; y también García de la Huerta, Theatro Hespañol, p. 347, Schack, Historia de la literatura y del arte dramático en España, p. 289; Hartzenbusch, Catálogo cronológico de las obras de D. Pedro Calderón de la Barca, p. 673; Münch-Bellinghausen, Über die älteren Sammlungen spanischer Dramen, p. 128; Schmidt, Die Schauspiele Calderón's dargestellt und erläutert, pp. 76-80; Rapp, Schauspiele von Calderón de la Barca, p. 20; Lasso de la Vega, Calderón de la Barca. Estudio de las obras de este insigne poeta, pp. 220-222; Günthner, Calderón und seine Werke, pp. 50-51; Schaeffer, Geschichte des spanischen Nationaldramas, p. 47; Cotarelo y Mori, 1922, pp. 43 y 117; Depta, 1925, pp. 97-99; Osma, 1928, pp. 221-226; Hilborn, 1938, pp. 20 у 34; Rundle, 1947-1948, pp. 104-111;Valbuena Briones, 1956, pp. 1127-1128.

${ }^{2}$ Ver Maione, 2015.
} 
Hartzenbusch señaló que la obra era anterior a $1635^{3}$. Schack, erróneamente, la sitúa en torno al 1646 o poco después ${ }^{4}$, Don Cruickshank cree que debió ser compuesta exactamente «entre agosto y septiembre de $1630 »^{5}$. Lo más plausible, si tenemos en cuenta algunas referencias internas de carácter histórico - las disputas por el Casale de Monferrato entre Francia y España en el contexto de la Guerra de Mantua-, es que Calderón escribiera nuestra comedia a lo largo de la primera mitad de la década de 1630.

La pieza dramática aparece en una colección de Diferentes $X X X I^{6}$, un volumen de la imprenta de Juan Sapera del año 1638. Aparece también recogida en una colección de Escogidas $\bar{T}$, en un tomo de Domingo García Morras del año 1652, aprobado por Calderón, y que al parecer no fue compuesta a partir de Diferentes XXXI. Por su parte, la edición de Vera Tassis, en la Octava parte de $1684^{8}$, parece haberla tomado de Escogidas I, ya que, entre otras cosas, ambas ediciones omiten un total de 58 versos con respecto a Diferentes XXXI. Don Cruickshank, en el estudio al que me he referido antes, señala que Diferentes XXXI y Escogidas I derivan separadamente de una copia del original que ya contenía errores. A su juicio, alguien que probablemente no fue el autor, debió de acortar el texto de la rama de Escogidas I, y opina que tampoco han de tomarse por espurios los versos adicionales de Diferentes XXXI . En cualquier caso, la edición de Escogidas I es menos descuidada que la de Diferentes XXXI. Existen también otras ediciones posteriores de la obra pertenecientes al siglo XVIII, salidas de diferentes imprentas, como es el caso de la de la imprenta de Antonio Sanz de 1746; el tomo quinto de las comedias que saca a la luz don Juan Fernández de Apontes de la imprenta del Supremo Consejo de la Inquisición, de 1761; la imprenta de

${ }^{3}$ Ver Hartzenbusch, Catálogo cronológico de las obras de D. Pedro Calderón de la Barca, p. 673.

${ }^{4}$ Schack, Historia de la literatura y del arte dramático en España, p. 289.

${ }^{5}$ Cruickshank, 2014, p. 91.

${ }^{6}$ Parte treinta y una de las mejores comedias que hasta hoy han salido, recogidas por el Doctor Francisco Toribio Jiménez. Disponible en: <http://www.cervantesvirtual.com/ nd/ark:/59851/bmctx3x3> [08/09/2016].

${ }^{7}$ Primera parte de comedias escogidas de los mejores de España. Disponible en: $<$ http://www. cervantesvirtual.com/nd/ark:/59851/bmcwq0k4> [08/09/2016].

8 Octava parte de comedias del célebre poeta español don Pedro Calderón de la Barca. Disponible en: <http://www.cervantesvirtual.com/nd/ark:/59851/bmct72x9>.

${ }^{9}$ Cruickshank, 2014, pp. 87-102. 
Francisco Suriá y Burgada (1770-1806); y finalmente la de la imprenta valenciana de los Orga de 1782. Entre las ediciones del siglo XIX, por destacar algunos ejemplos, pueden citarse las ediciones de la obra aparecidas en las colecciones de comedias de Keil $(1830)^{10}$ y de Hartzenbusch $(1849)^{11}$.

El título de la comedia —Con quien vengo, vengo-, de clara factura paremiológica, encuentra su explicación en el argumento, y a él se hace referencia hasta en dos ocasiones en el interior de la obra. Una se sitúa en la Jornada segunda, cuando el personaje de don Juan se enfrenta con la tesitura de defender a su amigo Otavio, con quien ha acudido a una comprometida cita amorosa con Leonor, a medianoche; o a don Sancho, también amigo pero hermano y guardián de la honra de Leonor, que les sorprende en tal circunstancia. Don Juan resuelve el dilema que se le plantea en tal tesitura poniéndose de parte de Otavio porque es con él con quien ha acudido a la comprometida cita ("Con quien vengo, vengo»). La otra ocasión se encuentra en la tercera jornada y se produce cuando Ursino, padre de don Juan, se ve en la obligación de elegir entre las opciones de defender a don Sancho, a quien ha prometido proteger, o a su propio hijo, que supuestamente ha ofendido el honor de don Sancho. Es decir, "Con quien vengo, vengo", una fórmula que se pretende vinculada con los requerimientos de las leyes del duelo ${ }^{12}$, plantea el núcleo temático central (más de carácter serio) de la obra: la disyuntiva dramática con la que entran en conflicto las relaciones familiares y de amistad y las convenciones sociales; pero, por otro lado, también su desarrollo argumental (más de carácter cómico): el enredo a que dan lugar las confusiones y cambios de papeles en que se ven envueltos los personajes por los equívocos de las situaciones. Así, el título de Con quien vengo, vengo recoge tanto el eje temático como la línea argumental de una trama que el versátil Calderón bien hubiera podido resolver trágicamente, pero que en esta comedia ha preferido diluir de forma magistral en un enredo de carácter cómico.

Los personajes principales de la comedia son dos parejas de damas y galanes: don Juan/Otavio y Leonor/Lisarda; un viejo, padre de don Juan, y un caballero, don Sancho, hermano de Leonor y Lisarda. A ellos se

${ }^{10}$ Las comedias de Don Pedro Calderón de la Barca, pp. 315-341.

${ }^{11}$ Comedias de Don Pedro Calderón de la Barca, pp. 233-254.

12 Para todo lo relacionado con la práctica y las leyes del duelo, ver Chauchadis, 1997. 
suma la figura del gracioso, Celio. El desarrollo argumental es el siguiente. La acción se desarrolla en Verona, donde don Juan y Otavio, —amigos desde los tiempos de estudiante en Bolonia- se encuentran con motivo de que este último ha venido a cumplir una misión secreta, para lo cual se aloja en casa de don Juan. La misión secreta de Otavio es vengarse de don Sancho, hermano de las dos damas, a causa de una antigua contienda amorosa. La acción comienza cuando Leonor, enamorada de Don Juan, lo convoca a través de un papel a una cita nocturna en su jardín, para lo cual encuentra la complicidad de su hermana Lisarda, que se ofrece a actuar como tercera de su secreto galanteo, disfrazándose de criada. A su vez, don Juan, aprovechando la estancia de su amigo Otavio, pretende acudir a la cita con la compañía de este, que se disfraza de criado para la ocasión, como Lisarda en el caso de su hermana. En efecto, los dos amantes - Leonor y don Juan — se encuentran en el jardín, donde mantienen su escena de galanteo. Simultáneamente al de don Juan y Leonor, los supuestos criados Nise (en realidad Lisarda) y el gracioso Celio (en realidad Otavio), también intercambian parlamentos amorosos cuya discreta fineza extraña tanto a una como a otro por impropia de la condición de criados. Pero la escena se ve interrumpida cuando se oye la llegada de don Sancho, guardián del honor de sus hermanas. Así concluye la jornada primera.

Lisarda, inquieta y perpleja por la atracción que el supuesto criado Celio (es decir, Otavio) le ha producido, lo cita a un encuentro nocturno en el jardín. Pero resulta que es el verdadero Celio, por encargo de su señor, quien aparece en la escena del jardín, y Lisarda, confundiéndolo, se dirige a él como si se tratara del «criado» (Otavio) de la noche anterior, y el diálogo que mantienen sume en la mayor de las perplejidades tanto al verdadero criado como a la dama: a Celio porque él sí reconoce a Lisarda; a Lisarda porque las finezas del disfrazado Otavio de la cita anterior se han trocado ahora en las necedades propias de un criado. El equívoco encuentro entre Celio y Lisarda se ve de pronto interrumpido por la aparición de don Sancho, lo que obliga a Celio a esconderse súbitamente en uno de los aposentos. Don Sancho aprovecha entonces la ocasión de encontrarse a solas con su hermana para confesarle la pendencia de amor que tuvo en Milán por la traición de una dama de la que estaba enamorado. Salido don Sancho de la estancia de Lisarda, Celio sale a su vez del paño y se despiden con el deseo de verse nuevamente a pesar del peligro de la vigilancia de don Sancho, que ya está alertado 
de la presencia de ciertos embozados que de noche rondan por su casa. Entran ahora en escena don Juan y Otavio, que de nuevo vuelven al jardín de las damas. Mientras esperan, Otavio termina de contarle a don Juan la causa de su viaje a Verona, que es el deseo de reparar el honor y el dolor de una dama milanesa, a cuyo amante mató un amigo suyo (don Sancho) que ahora vive en Verona. Aparece a continuación Celio, embozado, que llega a una nueva cita con Lisarda: la oscuridad de la noche y los disfraces dan lugar a una nueva escena de confusiones entre Otavio, don Juan, Celio y finalmente Lisarda, que ahora toma a don Juan por Otavio, a quien invita a entrar en su casa, para mayor perplejidad del verdadero Celio. Un breve diálogo de galanteo entre los galanes y las damas se ve nuevamente interrumpido por la llegada de don Sancho, que reconoce a Otavio y a don Juan. La situación, multiequívoca por los disfraces, la nocturnidad, la confusión de identidades y reconocimientos desemboca en una reyerta, cargada de escaramuzas entre damas, caballeros y criados, abrir y cerrar de puertas, entradas y salidas, caídas al jardín, acuchillamientos, etc., de los que finalmente don Sancho termina malherido. La reyerta nocturna concluye con una nueva confusión: Lisarda escapa con don Juan y Otavio, aunque estos creen llevar consigo a Leonor. La jornada termina con la aparición de Ursino, el padre de don Juan, que acude en ayuda de un don Sancho malherido, a quien promete hacerse cargo de su hermana Leonor.

La tercera jornada, que comienza justo a continuación de las escenas con que termina la segunda, sucede en su mayor parte en la casa de Ursino. Después del combate desarrollado en la segunda jornada, don Juan, con Otavio, Lisarda y Leonor, todo a oscuras, organizan un nuevo enredo en que se suceden todo tipo de confusiones entre los caballeros, las damas e incluso el criado Celio, sin que ninguno de ellos logre hacerse cargo de las identidades de cada uno; enredo al que se suman también unos desconcertados Ursino y don Sancho, y que al fin se resuelve con la revelación de todas las identidades, tanto las fingidas como las producidas por la oscuridad en que tiene lugar la acción. Otavio y Lisarda se confiesan sus secretos. Don Sancho, por su parte, desafia a don Juan y a Otavio, y Ursino, para cumplir con las promesas que le hizo a Don Sancho sobre él y sobre la protección del honor de su hermana Leonor, se pone del lado de don Sancho para luchar contra su hijo. En esta tesitura, termina interviniendo la justicia, pero las damas ponen solución al problema, declarando su voluntad de casamiento: Leonor con 
don Juan y Lisarda con Otavio. De esta manera queda salvaguardado el principio del honor y el triunfo del amor. Con lo que concluye la comedia.

Con quien vengo, vengo es una comedia de "capa y espada» (o, si se prefiere, una comedia cómica de espacio urbano), que Bances Candamo definía como «aquéllas cuyos personajes son sólo caballeros particulares, como don Juan, y don Diego, etcétera, y los lances se reducen a duelos, a celos, a esconderse el galán, a taparse la dama, y en fin a aquellos sucesos más caseros de un galanteo» ${ }^{13}$. A la básica definición y características de Bances responde nuestra comedia calderoniana, que, como acabamos de ver, tiene el amor como tema nuclear, protagonizado por unos personajes pertenecientes al estamento de la caballería urbana - don Juan, Otavio y don Sancho-, que llevan a cabo una acción ambientada en la coetaneidad de la vida española del siglo xviI y desarrollan un enredo dramático — juegos de identidad, fingimientos, escenas de disfracesen el que los lances de amor van acompañados por escenas de duelos que contravienen las leyes o las convenciones del honor ${ }^{14}$.

Ignacio Arellano, en su caracterización de la comedia de capa y espada, ha insistido en la importancia del universo lúdico, no trágico, destacando la concentración temporal y espacial con tendencia a las unidades de tiempo y lugar, provocadoras de inverosimilitud entretenida y sorprendente, la ruptura del decoro, generalización de agentes cómicos, con tratamiento humorístico del honor, marcas de inserción en la coetaneidad y cercanía (geográfica, cronología, onomástica), primordial objetivo del enredo y dinamismo suspensivo ${ }^{15}$. Por su parte, Fréderic Serralta, al intentar trazar una definición para el género «comedia de enredo", señala que la comedia de enredo sería con frecuencia una comedia de capa y espada; sería, en estricto sentido, aquella en que el enredo es lo más presente y lo más importante de toda la obra ${ }^{16}$.

La temática, el argumento y la factura de Con quien vengo, vengo cumplen prácticamente con los rasgos genéricos referidos. En primer lugar, el tiempo dramático transcurre en el límite temporal de dos noches, con lo que de esta forma «la unidad de tiempo no se desliga de la construcción laberíntica de la trama ingeniosa ni de la acumulación de enredos

\footnotetext{
13 Ver Sánchez Escribano y Porqueras Mayo, 1972, p. 347.

${ }^{14}$ Ver Chauchadis, 1997, pp. 127-136, 205-226, 325-357 y 391-415.

15 Arellano, 1988, p. 48, y 1994, pp. 103-128.

16 Serralta, 1988, p. 131.
} 
cuyos efectos potencia» ${ }^{17}$, y la acción se desarrolla en un espacio concreto, en la calle y entre las casas de Leonor y de don Juan. Por otra parte, el enredo general está motivado por un continuo trueque de identidades que, de acuerdo con las convenciones del género, constituyen la trama y producen los correspondientes efectos de comicidad. Tal comicidad deriva, por otro lado, del "pacto» con el espectador, buen conocedor de las convenciones del género, al que se le dedican continuos guiños mediante los recursos teatrales de los apartes, escuchas «al paño», etc., que advertía al público de la complejidad de la trama y lo colocaba en una posición ventajosa con respecto a la identidad de los personajes ${ }^{18}$. Es de destacar que en Con quien vengo, vengo Calderón encarga la gestión de la comicidad no solo al habitual personaje del gracioso (Celio en este caso) sino también a los personajes nobles, disfrazados de criados, haciendo un regate burlón tanto a la preceptiva dramática como a las convenciones sociales.

Según hemos podido observar en el resumen argumental, como si Calderón no deseara dar la mínima tregua a la atención del espectador, el enredo de Con quien vengo, vengo comienza desde el primer momento, cuando Leonor y Lisarda aparecen en escena disputándose la posesión de un papel a través del cual Leonor convoca a su desconocido enamorado a una cita nocturna en su jardín, cita para la que logra la complicidad de su hermana Lisarda, que se ofrece como alcahueta de su secreto galanteo, disfrazándose de criada:

\footnotetext{
Mas oye lo que he pensado para asegurarme a mí y no embarazarte a ti la esperanza de tu estado. En traje disimulado yo tu criada he de ser de noche, porque he de ver si es tan honesto el empleo de tu amor y tu deseo como me das a entender. $[\ldots]$
}

17 Ver Arellano, 1988, p. 32.

${ }^{18}$ Díez Borque, 2011, p. 32. 
Envía, pues, el papel y empiece el engaño hoy ${ }^{19}$.

Y poco después, en la analepsis en que Otavio le relata a su amigo don Juan los avatares que lo han traído a Verona en misión secreta para vengarse de don Sancho por una antigua contienda amorosa, se adelantan algunos de los motivos estructurales que darán lugar a los enredos subsiguientes en que consistirá la comedia:
Una dama por quien muerto
de amores está, un amigo
de quien se queja con celos,
un duque a quien encarece, y a mí, a quien tiene propuesto que le tengo de valer.
Pues de la farsa que emprendo todos somos personajes, todos nuestra parte hacemos ${ }^{20}$.

Todos los personajes "haciendo su parte», como anuncia Otavio, es decir, con sus distintas motivaciones, irán dando lugar a partir de ese momento a una compleja maraña de situaciones dramáticas, para la cual Calderón explotará con gran habilidad todos los recursos acostumbrados - y ya convencionales- de la comedia de enredo: el trueque de identidades, los disfraces, los engaños, las confusiones al amparo de la nocturnidad o, para expresarlo con la frescura del mismo Otavio en la analepsis de la Jornada primera a la que acabo de referirme: «ventana, calle y terrero, / señas, papeles, criados, / noches, embozos, paseos $»^{21}$.

En efecto, Calderón irá distribuyendo a lo largo de la comedia, en una escala de gradación ascendente y de la mano de los diversos agentes de la comicidad, las situaciones confusas de un embrollo incesante que mantendrán viva la atención de los espectadores, provocando tanto su entretenimiento como su hilaridad ${ }^{22}$. Prácticamente toda la acción de Con quien vengo, vengo se desarrolla en la nocturnidad, a cuyo amparo

${ }^{19}$ Con quien vengo, vengo, p. 1131a. Cito por la edición de Valbuena Briones, 1973.

${ }^{20}$ Con quien vengo, vengo, p. $1155 \mathrm{a}$.

${ }^{21}$ Con quien vengo, vengo, p. $1134 \mathrm{a}$.

22 Ver el trabajo de Arellano, 1986, pp. 47-92, donde estudia y deslinda los diversos recursos de la comicidad calderoniana en un buen corpus de comedias. 
se van produciendo las sucesivas fases del enredo general. En la primera jornada se sitúa solo en una ocasión el fingimiento de identidades: se trata de la primera cita de galanteo en el jardín entre don Juan y Leonor, en la que Lisarda y Otavio, galanteando a su vez, fingen ser respectivamente los criados Nise y Celio, y desconcertándose el uno al otro al emplear en su diálogo tanto el estilo vulgar propio de los criados como el refinamiento noble; escena que se ve pronto truncada por la irrupción de don Sancho, que obliga a los enamorados a una rápida huida.

Pero ya desde el principio de la segunda jornada y en todo su transcurso, partiendo de los fingimientos de identidad anunciados, se produce una cadena de confusiones en la sucesión de diversas escenas: 1) cuando Juan y Otavio ordenan al verdadero criado (Celio) que busque a Nise (con la intención de preparar el inmediato encuentro de los enamorados), encargo que desconcierta al propio Celio, extrañeza que aumenta cuando responde a su llamada Lisarda (a quien reconoce el criado), que también se sorprende (sin reconocer a Celio) de la mutación del «talle» y de las «frías necedades» del galán (que ella cree Otavio) con el que galanteó la noche anterior. Pero de nuevo la escena es interrumpida por la llegada de don Sancho, lo que obliga a Lisarda a esconder a Celio en un aposento; 2) cuando, ya terminado el diálogo a solas entre Lisarda y su hermano, abandona don Sancho la escena, Celio reaparece desde el «paño» y Lisarda, totalmente desorientada sobre la identidad y por el comportamiento de Celio, vacila entre despedir definitivamente al supuesto galán o mantener sus citas con él, actitud de la dama que sume al criado aún en mayor desconcierto; 3) cuando, en la segunda cita nocturna entre las damas y los caballeros, mientras estos merodean por la calle de Leonor y Lisarda, llega a la escena también el verdadero Celio (disfrazado de caballero), de modo que al aparecer Lisarda llamando al supuesto Celio (Otavio) responden al mismo tiempo el verdadero Celio y el supuesto (Otavio). Los caballeros entran en la casa de las damas, pero su encuentro se ve estorbado por la irrupción de don Sancho, que espiaba secretamente a los merodeadores. Los galanes tratan precipitadamente de huir, pero Otavio no logra zafarse, y en el alboroto que se organiza durante la pelea se produce una cadena de nuevas y diversas confusiones cuando al fin todos logran escapar de la reyerta: Lisarda toma a Otavio por don Juan, Otavio toma a Leonor por Lisarda, don Juan toma a Lisarda por Leonor. 
En la pelea de don Sancho con los galanes se pone fin a la segunda jornada, del que ha resultado también el reconocimiento de Otavio por el hermano de las damas. La tercera jornada se desarrolla a partir del embrollo de identidades organizado. Durante todo el tiempo de la estancia de damas y galanes en distintos aposentos de la casa de don Juan, escondidas de la persecución de don Sancho, se mantiene la confusión de identidades: don Juan piensa que la dama a la que está protegiendo es Leonor (en realidad, Lisarda); Lisarda, que ha reconocido al verdadero Celio, sigue creyendo que su protector es don Juan, cuando en realidad se trata de Otavio. Otro juego de equívocos, siempre al amparo de la noche y por el movimiento de los personajes en los distintos espacios interiores, se produce cuando aparece en escena el padre de don Juan (Ursino), comprometido en la defensa del honor de don Sancho: ahora se trueca la identidad de las damas, y Ursino toma a Lisarda por Leonor, Otavio toma a Leonor por Lisarda, Celio confunde a Leonor con Lisarda... Como no podía ser de otra manera, la comedia termina en un lieto fine cuando, en presencia del gobernador de Verona, se desvelan las verdaderas identidades de las damas y los caballeros, Lisarda se promete a Otavio; Leonor, a don Juan, y don Sancho y Otavio se reconcilian.

Si la oscuridad de la noche es la que posibilita las suplantaciones y confusiones de personalidad, haciendo teatralmente verosímil el enredo cómico de Con quien vengo, vengo, en ello participa también en igual medida el uso de los disfraces (o embozamientos), tan frecuentes en la comedia de enredo ${ }^{23}$, a los que se hace referencia continua, tanto en el caso de los personajes masculinos como femeninos. Gracias a un disfraz Lisarda se trocará de dama en criada para favorecer los amores de su hermana con don Juan: «En traje disimulado / yo tu criada he de ser / de noche, porque he de ver / si es tan honesto el empleo / de tu amor y tu deseo / como me das a entender» $»^{24}$; Otavio llega aVerona «encubierto ${ }^{25}$ para cumplir su misión secreta; don Juan pide al criado que le procure una "capa» y un «broquel» para acudir embozado a su primera cita con Leonor embozado ${ }^{26}$, cita en la que Lisarda ya aparece disfrazada

${ }^{23}$ Ver Serralta, 1988, p. 132. Para un estudio de conjunto sobre el motivo del disfraz en las comedias calderonianas, ver Escalonilla, 2004.

${ }^{24}$ Con quien vengo, vengo, p. 1131a.

${ }^{25}$ Con quien vengo, vengo, p. 1133a.

${ }^{26}$ Con quien vengo, vengo, pp. 1137a, $1137 \mathrm{~b}$. 
de criada, como indica la acotación correspondiente ${ }^{27}$. En la jornada segunda, tales conductas de ocultación no dejan de sorprender al criado Celio («No sé qué enigmas son estas. / Ellos que vienen de noche / con disfraces y cautelas» ${ }^{28}$; el mismo Celio concurre a la cita nocturna con Lisarda, a quien cree su enamorada por haberlo confundido con Otavio, disfrazado de señor ("con capa rica», acotación) ${ }^{29}$, disfraz del que se extraña el mismo Otavio al verlo («Pues ¿qué disfraz es aqueste?»), a lo que responde Celio:
Disfraz de hombre enamorado, que no hay cosa en que no se eche de ver más, cuando lo están, que en andar limpias las gentes ${ }^{30}$.

Junto al ambiente de nocturnidad casi permanente y a la utilización de los disfraces por parte de las dos parejas de enamorados, conductores de la trama (Leonor, don Juan/Lisarda, Otavio), aún ha de hacerse referencia a otro recurso más que coadyuva significativamente tanto al enredo general de la trama como a su recepción cómica entre los espectadores. Se trata de la estructuración del espacio escénico por el se mueven los personajes, al hilo de las peripecias de la acción. Con quien vengo, vengo es, en este último aspecto, un alarde dramático de Calderón, que ha explotado sabiamente todas las posibilidades espaciales que le brindaban los teatros, bien familiares para un público acostumbrado a las convenciones de la comedia cómica, de tal forma que por su misma variedad también justificara la confusión. En efecto, la acción discurre en varios espacios interiores - la casa de don Sancho, la casa y el jardín de Ursino- y exteriores - la calle, el campo-. Pero de dichos espacios, como digo, se extraen todas sus posibilidades escénicas cuando los incidentes y lances del enredo obligan a los personajes a moverse entre y a través de ellos para burlar las consecuencias de las circunstancias imprevistas (las irrupciones de don Sancho, por ejemplo). Entonces la acción pasa del tempo lento de una escena amorosa a un tempo rápido en el que los personajes han de evolucionar nerviosamente del jardín a la calle, de la calle al jardín, entre las diversas estancias de la casa de Ursino,

\footnotetext{
27 Con quien vengo, vengo, p. $1137 \mathrm{~b}$.

${ }^{28}$ Con quien vengo, vengo, p. $1142 \mathrm{~b}$.

29 Con quien vengo, vengo, p. $1147 \mathrm{~b}$.

${ }^{30}$ Con quien vengo, vengo, p. $1148 \mathrm{a}$.
} 
de un cuarto a otro, en un vertiginoso abrir y cerrar de puertas y portales, subidas y bajadas, todo acompañado de ruidos, peleas, etc.

Todos los soportes y factores del enredo a los que me acabo de referir - la nocturnidad, los disfraces, los espacios, las ocultaciones y trueques de identidad - van formando a lo largo de la comedia una especie de boule de neige de situaciones equívocas y confusiones en las que participan todos los personajes, de modo que podríamos decir que la comicidad general de Con quien vengo, vengo deriva de lo que Bergson denominaba "comique des formes et de mouvements» $\mathrm{y}$ "comique de situation" más que de lo "comique de caractère" ${ }^{31}$. Ahora bien, si la figura del gracioso (Celio) no desempeña en esta comedia el papel de agente único de lo cómico ni tampoco el privilegiado papel-motor del enredo, a él se le encomiendan, sin embargo, otros recursos de la comicidad que mantienen viva la inteligencia de los espectadores sobre lo que ocurre en la escena y aumentan el carácter jocoso de situaciones y personajes. Él mismo resulta víctima de las confusiones del enredo cuando Lisarda lo toma por Otavio, y el criado, creyendo que la dama se ha enamorado de él, se disfraza de caballero con la intención de galantear con ella. Tal trueque de identidades sociales entre dama (criada) y criado (galán), aunque fugaz en la escenificación, debió de representar para los espectadores de la comedia uno de los momentos de mayor efecto cómico.

El personaje de Celio responde a las características de los criados y graciosos de comedia: cobarde, desvergonzado, interesado, ruin y murmurador. Como cobarde se muestra cuando acude por primera vez a la casa de Lisarda para recoger el papel de la cita con su señor con la excusa de cobrar una deuda y teme ser despedido a palos por la dama:

LISARDA

Decid presto a quién buscáis,

o haré que por atrevido

mil palos, villano, os den

dos esclavos.

Celio

No harán bien

en darme lo que no pido.

Mi conciencia acomodada

corre, porque desto gusta,

siempre abierta y nunca justa,

31 Bergson, 1924.Ver también Domínguez Matito, 2013, pp. 639-653. 
por no verse empalizada;

y tanto se sutiliza

el temor, que de mi casa

no salgo el día que pasa

por ella Mons de Paliza.

Y así, por que revoquéis,

diosa Palas, la paluna

sentencia, ved que ninguna

causa contra mí tenéis ${ }^{32}$.

Desvergonzado, como, por ejemplo, cuando es sorprendido por don Sancho hablando con Lisarda:

Don SANCho ¿De quién sois crïado vos?

Celio De Dios.

Don SANChO ¡Lindo desenfado!

Celio Si Dios todo lo ha crïado, ¿quién no es criado de Dios?

Y si argumentos tan buenos

no os dejan asegurado,

pruebo que soy su crïado

en que es a quien sirvo menos ${ }^{33}$.

Interesado y ruin, al pretender cobrar a su señor por los favores, negándole la entrega del papel de la cita con Leonor si antes no recibe la paga:

Y si quien trae buenas nuevas

y quien las dice de presto,

albricias nuevas merece,

papel hay, venga dinero;

y si no, no habrá papel ${ }^{34}$.

Y murmurador, cuando descubre la confusión que se ha producido entre él y Otavio en los favores amorosos de Lisarda:

${ }^{32}$ Con quien vengo, vengo, p. $1131 \mathrm{~b}$.

${ }^{33}$ Con quien vengo, vengo, p. 1132a.

${ }^{34}$ Con quien vengo, vengo, p. $1136 \mathrm{~b}$. 


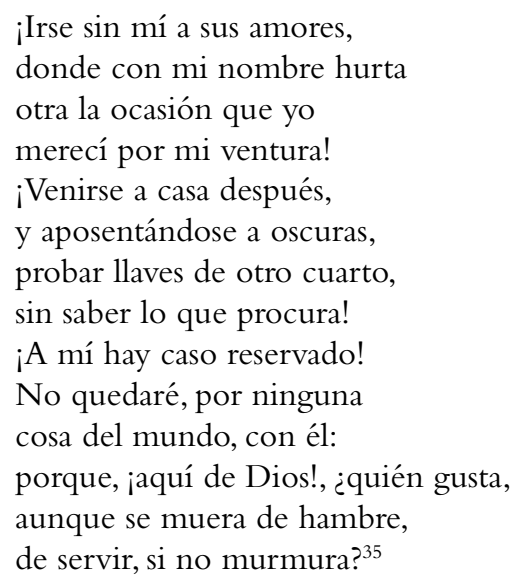

Siempre en connivencia con el público, hace comentarios de carácter jocoso, mediante continuos parlamentos aparte, sobre los personajes o las circunstancias de la trama para asegurar el sentido del juego cómico. Así, no deja de proferir expresiones interjectivas sobre cualquiera de las incidencias relacionadas con las confusiones del enredo: «iCielos! ¿Quién ha de entender / la cifra de aqueste enfado?»; « No es la tramoya muy mala!»; «Mas ¡qué es esto, santo cielo!»; «iCosa extraña!»; «jesús!». E incluso llega a hacer burlas con el mismo título de la comedia ( $\mathrm{Y}$ mi capricho / se atiene a lo dicho, dicho»). Murmura, en aparte para los espectadores, sobre Lisarda («Esta mujer es el diablo»; «Dos mil demonios la valgan») y se burla de Otavio («Eres un atún de requiem»).

El gracioso Celio recurre frecuentemente a diversas formas del juego lingüístico (neologismo, calambur, polisemia, etc.) para hacer sus chistes, como por ejemplo, «iQué es daca! Primero / he de tomacar»; o este otro caso, sobre el trueque de Nise con Lisarda:

Nise fue mi remoquete un tiempo; mas ya no es Nise, ni se dice, ni se puede decir, porque al fin fue amor de medio mogate ese, y este de mogate entero ${ }^{36}$;

${ }^{35}$ Con quien vengo, vengo, p. $1154 \mathrm{a}-\mathrm{b}$.

${ }^{36}$ Con quien vengo, vengo, p. $1148 \mathrm{a}$. 
o cuando discute con Otavio, jugando con el doble sentido de la palabra 'punto':

Otavio Pues váyase de aquí al punto.

Celio Dónde es el punto conviene a saber si he de ir allá, si no es que decirme quiere que irme al punto es irme al punto.

Otavio No del vocablo me juegue, sino váyase ${ }^{37}$;

o, en fin, cuando requiebra torpemente a Lisarda, jugando con los títulos nobiliarios en una gradación descendente, que la dama considera "frías necedades», «frialdades tan necias» y provocan su rechazo:

Y si es que os nombrara, fuera por diosa de la hermosura, por ninfa de la belleza, emperatriz de la gala y de la discreción reina, archiduquesa del garbo, de lo prendido duquesa marquesa de lo parlado, y del aseo condesa, y vizcondesa de nada. Que no ha de ser vizcondesa Lisarda, si en la demanda perder un ojo me cuesta; que menos importara, para lo de Dios, que sea yo, hermosa señora mía, bizco, que vos vizcondesa ${ }^{38}$.

Para sus gracias con los juegos de palabras, Celio ironiza también con las referencias históricas y mitológicas, como esta sobre el general francés Monsieur de Paliza y la diosa Palas:

37 Con quien vengo, vengo, p. $1147 \mathrm{~b}$.

${ }^{38}$ Con quien vengo, vengo, p. $1142 \mathrm{~b}$. 


\begin{abstract}
Y tanto se sutiliza
el temor, que de mi casa

no salgo el día que pasa

por ella Mons de Paliza.

$Y$ así, porque revoquéis,

Diosa Palas, la paluna

sentencia, ved que ninguna

causa contra mí tenéis ${ }^{39}$;
\end{abstract}

con las citas clásicas, como esta tomada de la Eneida, X, 284 ("Audentes Fortuna iuvat timidosque repellit»):

No faltará una cautela;

que a los audaces, sin duda,

dicen que Fortuna ayuda,

y a los tímidos repela ${ }^{40}$;

o con expresiones que corresponden al lenguaje propio de la judicatura:

Y así digo que al oficio

de la querella el proceso

se lleve, por que mejor

fulminado el caso esté,

y que yo responderé

allá por procurador ${ }^{41}$.

Para concluir, Con quien vengo vengo pone de manifiesto las dotes de Calderón para la comicidad, de la que en esta comedia hace el mismo alarde que puede verse en otras muchas de sus comedias de enredo, como El acaso y el error, Agradecer y no amar, Bien vengas mal, si vienes solo, La dama duende, El escondido y la tapada, El maestro de danzar, Peor está que estaba, Manos blancas no ofenden, Los tres afectos de amor, La señora y la criada, La selva confusa, etc. Pero en esta obra creemos no tener simplemente una muestra más de las comedias de enredo a base de disfraces y confusiones de identidad, recursos tan traídos y llevados por la comedia áurea desde Lope $^{42}$. El genio calderoniano ha sumado a su compleja

\footnotetext{
39 Con quien vengo, vengo, p. $1131 \mathrm{~b}$.

${ }^{40}$ Con quien vengo, vengo, p. $1131 \mathrm{a}$.

41 Con quien vengo, vengo, p. $1131 \mathrm{~b}$.

42 Ver Díez Borque, 2011, pp. 33-36.
} 
construcción de una trama hilarante para divertir a los espectadores una serie de ingredientes que quizá pretenden ir un poco más allá de la simple comicidad. Porque si es verdad que el enredo, las confusiones, los disfraces sumergen permanentemente al espectador en el territorio de la sorpresa, de la risa, en un incesante devenir, Con quien vengo, vengo plantea, por debajo o por encima de las vicisitudes de la comicidad de la trama temas más serios sobre los que la comedia invita a reflexionar: el cuestionamiento de las relaciones amorosas entre personas de supuesta condición social desigual y las limitaciones de los códigos del amor y del honor cuando entran en conflicto con las relaciones familiares y de amistad. 


\section{BibLIOGRAFÍA}

Arellano, Ignacio, «La comicidad escénica en Calderón», Bulletin Hispanique, 88, 1986, pp. 47-92.

Arellano, Ignacio, «Convención y rasgos genéricos en la comedia de capa y espada», en La comedia de capa y espada, Madrid, Ministerio de Cultura, 1988, pp. 27-49.

Arellano, Ignacio, «La generalización del agente cómico en la comedia de capa y espada», Criticón, 60, 1994, pp. 103-128.

Bergson, Henri Bergson, Le rire. Essai sur la signification du comique, Paris, Alcan, 1924.

Calderón de la Barca, Pedro, Las comedias de Don Pedro Calderón de la Barca, tomo IV, ed. Juan Jorge Keil, Leipsique, Ernesto Fleischer, 1830.

Calderón de la Barca, Pedro, Comedias de Don Pedro Calderón de la Barca, tomo II, ed. Juan Eugenio Hartzenbusch, Madrid, Rivadeneyra, 1849.

Calderón de la Barca, Pedro, Calderón, Obras Completas, II, ed. ÁngelValbuena Briones, Madrid, Aguilar, 1956.

Calderón de la Barca, Pedro, Con quien vengo, vengo, en Obras completas, tomo II. Comedias, ed. Ángel Valbuena Briones, Madrid, Aguilar, 1973, pp. 11291165.

Cotarelo y Mori,Emilio, «Ensayo sobre la vida y obras de Don Pedro Calderón de la Barca», Boletín de la Real Academia Española, 8, 1922, pp. 43-177.

Cruickshank, Don William, «Juan de Vera Tassis y Con quien vengo, vengo», en Diferentes y escogidas: Homenaje al profesor Luis Iglesias Feijoo, ed. Santiago Fernández Mosquera, Madrid/Frankfurt, Iberoamericana/Vervuert, 2014, pp. 87-102.

Chauchadis, Claude, La loi du duel. Le code du point d'honneur dans l'Espagne des XVIT-XVII siècles, Toulouse, Presses Universitaires du Mirail, 1997.

Depta, Max Victor, Pedro Calderón de la Barca, Leipzig, Quelle \& Meyer, 1925.

Díez Borque, José María, «El disfraz y otras estrategias para el éxito de la comedia», en Máscaras y juegos de identidad en el teatro español del siglo de oro, ed. María Luisa Lobato, Madrid,Visor, 2011, pp. 21-36.

Domínguez Matito, Francisco, «Nobles ridículos: observaciones sobre la transversalidad de lo grotesco en el teatro áureo», Rilce, 29, 3, 2013, pp. 639-653.

Escalonilla, Rosa Ana, La dramaturgia del disfraz en Calderón, Pamplona, Eunsa, 2004.

García de la Huerta, Vicente, Theatro Hespañol, I, Madrid, Imprenta Real, 1785.

Günthner, Engelbert, Calderón und seine Werke, II, Freiburg, Herder, 1888.

Hartzenbusch, Juan Eugenio, Catálogo cronológico de las obras de D. Pedro Calderón de la Barca, en Obras de Don Pedro Calderón de la Barca, IV, Madrid, Rivadeneyra, 1850, pp. 661-682. 
Hilborn, Harry, A Chronology of the Plays of Don Pedro Calderón, Toronto, University of Toronto Press, 1938.

Lasso de la Vega, Ángel, Calderón de la Barca. Estudio de las obras de este insigne poeta, Madrid, Tello, 1881.

Maione, Paologiovanni, "Uno spettacolo a misura del 'particolari': Con chi vengo vengo a palazzo Girifalco (Napoli 1665)», Anuario Calderoniano, 8, 2015, pp. 245-266.

MünCh-Bellinghausen, Freiherr Eligius von, Über die älteren Sammlungen spanischer Dramen, Wien, Kaiserlich-Königliche Hof und Staatsdruckerei, 1852.

Osma, José M. de, «Notas a la comedia Con quien vengo, vengo», Hispania, 11, 3, 1928, pp. 221-226.

Rapp, Moriz, Schauspiele von Calderón de la Barca, Spanisches Theater, Hildburghausen, Bibliographisches Institut, 1868-1870.

Sánchez Escribano, Federico y Alberto Porqueras Mayo, Preceptiva dramática española del Renacimiento y el Barroco, Madrid, Gredos, 1972.

Serralta, Fréderic, «El enredo y la comedia: deslinde preliminar», Criticón, 42, 1988, pp. $125-137$.

Schacк, Adolfo Federico, Conde de, Historia de la literatura y del arte dramático en España, V, Madrid, Imprenta y Fundición de M. Tello, 1887.

SchAEFFER, Adolf, Geschichte des spanischen Nationaldramas, II, Leipzig, Brockhaus, 1890.

SснміDт, Friedrich, Die Schauspiele Calderón's dargestellt und erläutert, Elberfeld, 1857. 